Portland State University

PDXScholar

$12-1-2011$

\title{
Defining Conservation Priorities for Freshwater Fishes According to Taxonomic, Functional, and Phylogenetic Diversity
}

\author{
Angela L. Strecker \\ Portland State University, angela.strecker@wwu.edu \\ Julian D. Olden \\ University of Washington - Seattle Campus \\ Joanna B. Whittier \\ University of Missouri \\ Craig Patrick Paukert \\ University of Missouri
}

Follow this and additional works at: https://pdxscholar.library.pdx.edu/esm_fac

Part of the Environmental Sciences Commons

Let us know how access to this document benefits you.

\section{Citation Details}

Strecker, Angela L., Julian D. Olden, Joanna B. Whittier, and Craig P. Paukert. 2011. Defining conservation priorities for freshwater fishes according to taxonomic, functional, and phylogenetic diversity. Ecological Applications 21:3002-3013.

This Article is brought to you for free and open access. It has been accepted for inclusion in Environmental Science and Management Faculty Publications and Presentations by an authorized administrator of PDXScholar. Please contact us if we can make this document more accessible: pdxscholar@pdx.edu. 


\title{
Defining conservation priorities for freshwater fishes according to taxonomic, functional, and phylogenetic diversity
}

\author{
Angela L. Strecker,${ }^{1,4}$ Julian D. Oldenn, ${ }^{1}$ Joanna B. Whittier,${ }^{2}$ and Craig P. Paukert ${ }^{3}$ \\ ${ }^{1}$ School of Aquatic and Fishery Sciences, University of Washington, Seattle, Washington 98105 USA \\ ${ }^{2}$ Department of Fisheries and Wildlife Sciences, University of Missouri, Columbia, Missouri 65211 USA \\ ${ }^{3}$ U.S. Geological Survey, Missouri Cooperative Fish and Wildlife Research Unit, Department of Fisheries and Wildlife Sciences, \\ University of Missouri, Columbia, Missouri 65211 USA
}

\begin{abstract}
To date, the predominant use of systematic conservation planning has been to evaluate and conserve areas of high terrestrial biodiversity. Although studies in freshwater ecosystems have received recent attention, research has rarely considered the potential tradeoffs between protecting different dimensions of biodiversity and the ecological processes that maintain diversity. We provide the first systematic prioritization for freshwaters (focusing on the highly threatened and globally distinct fish fauna of the Lower Colorado River Basin, USA) simultaneously considering scenarios of: taxonomic, functional, and phylogenetic diversity; contemporary threats to biodiversity (including interactions with nonnative species); and future climate change and human population growth. There was $75 \%$ congruence between areas of highest conservation priority for different aspects of biodiversity, suggesting that conservation efforts can concurrently achieve strong complementarity among all types of diversity. However, sizable fractions of the landscape were incongruent across conservation priorities for different diversity scenarios, underscoring the importance of considering multiple dimensions of biodiversity and highlighting catchments that contribute disproportionately to taxonomic, functional, and phylogenetic diversity in the region. Regions of projected human population growth were not concordant with conservation priorities; however, higher human population abundance will likely have indirect effects on native biodiversity by increasing demand for water. This will come in direct conflict with projected reductions in precipitation and warmer temperatures, which have substantial overlap with regions of high contemporary diversity. Native and endemic fishes in arid ecosystems are critically endangered by both current and future threats, but our results highlight the use of systematic conservation planning for the optimal allocation of limited resources that incorporates multiple and complementary conservation values describing taxonomic, functional, and phylogenetic diversity.
\end{abstract}

Key words: anthropogenic stressors; desert rivers; endangered species; Lower Colorado River Basin; restoration; systematic conservation planning.

\section{INTRODUCTION}

Despite mounting recognition that freshwater biodiversity is severely threatened (Vörösmarty et al. 2010), conservation planning for these habitats continues to lag far behind that of terrestrial and marine systems (Abell et al. 2007). Freshwater ecosystems present unique challenges for conservation planning because of the need to consider both upstream and downstream processes, including threats that originate outside the watershed of interest ( Nel et al. 2009, Linke et al. 2011). With the recent development of conservation tools specifically oriented to aquatic systems (Moilanen et al. 2008, Hermoso et al. 2011), conservation planning and the development of freshwater protected areas have

Manuscript received 5 April 2011; revised 9 June 2011; accepted 13 June 2011. Corresponding Editor: C. Nilsson.

${ }^{4}$ Present address: Department of Environmental Science and Management, Portland State University, Portland, Oregon 97207 USA. E-mail: strecker@pdx.edu become a burgeoning field of research, incorporating aspects of complementarity, connectivity, and network prioritization specific to riverine systems (Abell et al. 2007, Leathwick et al. 2010, Esselman and Allan 2011).

Notwithstanding recent advances, many critical gaps in our knowledge still exist. First, maintaining biotic interactions such as connectivity between consumers and their resources is rarely considered in freshwater conservation strategies, despite its importance in terrestrial conservation planning (Rayfield et al. 2009). Invasive species may have strong competitive or predatory interactions with native species, and therefore, conservation strategies might attempt to reduce the frequency of these interactions. Second, the development of robust conservation strategies will need to utilize information on both contemporary and future threats to maximize long-term species persistence (Nel et al. 2009). In a survey of conservation planning studies, which typically include information on species distributions and static threats, only $2 \%$ of papers considered 
dynamic threats and biotic interactions or processes (Pressey et al. 2007), overlooking the importance of human influences and the natural processes that maintain species diversity (e.g., Klein et al. 2009).

Systematic conservation planning has also traditionally focused on identifying priority areas that ensure adequate representation of measures of taxonomic diversity, such as species richness (Margules and Pressey 2000). However, it is now well recognized that functional and phylogenetic (i.e., cladistic [Faith 1992]) relationships among taxa are key ecological and evolutionary determinants of biodiversity. Functional diversity measures the number, type, and distribution of functions performed by organisms within an ecosystem, and thus considers the complementarity and redundancy of cooccurring species (Díaz and Cabido 2001). Functional diversity is commonly assumed to be a better predictor of ecosystem productivity and vulnerability than species diversity (Hooper et al. 2005). Phylogenetic diversity describes the evolutionary history represented by a set of species and the potential for future diversifications (Faith 1992, Forest et al. 2007). Recent studies have acknowledged that regions of high taxonomic diversity may be incongruent with regions of high functional or phylogenetic diversity (Forest et al. 2007, Cumming and Child 2009), and that spatial discrepancies between different aspects of diversity may result in conservation strategies that do not fully represent biodiversity (Devictor et al. 2010). Emerging from this is a clear and urgent need for systematic conservation planning that accounts for multiple different aspects of biological diversity reflecting taxonomic, functional, and evolutionary perspectives.

Our study provides the first systematic prioritization for freshwaters that incorporates multiple (and complementary) conservation values describing fish taxonomic, functional, and phylogenetic diversity. Our focus is the Lower Colorado River Basin (Fig. 1A), which is considered one of the most human-altered rivers in the world, and where virtually every drop of its water is managed, accounted for, and allocated for use by millions of people in the American Southwest (Sabo et al. 2010). Our objective was to test the concordance of different conservation strategies under scenarios of contemporary threats to biodiversity (e.g., river regulation and fragmentation by dams, human land use), as well as under projections of future climate change and human population growth. The basin is an ideal study system because: (1) it contains a globally unique fish fauna, (2) there is evidence of discordance between fish taxonomic and functional diversity (Olden et al. 2006), and (3) past conservation planning efforts have focused solely on taxonomic diversity (Turner and List 2006), ignoring potential spatial disconnect between biodiversity metrics. Further, we explicitly incorporate interactions between nonnative and native species into conservation scenarios, as the Lower Colorado River Basin has the dubious distinction of being a global invasion hotspot (Leprieur et al. 2008), where the number of nonnative fish species are more than double the number of native species (Olden and Poff 2005). Our study contributes to the growing field of conservation planning in freshwaters by utilizing complex heuristic algorithms to account for trade-offs among different contending factors (e.g., nonnative species, contemporary threats), which has been identified as a significant contributor to the successful implementation of conservation actions (Barmuta et al. 2011).

\section{Materials And Methods Species distribution models}

We developed a comprehensive database containing $>1.8$ million fish records for native and nonnative fishes in the Lower Colorado River Basin covering the period from 1840 to 2009 (Whittier et al. 2011). Records include incidence, identity, and collection information for the complete holdings of major museum collections, numerous smaller holdings, and records from state agencies, peer review, and gray literature sources. The focus of our study was on 1.66 million fish records collected post-1980, which has been identified as a representative time period reflecting present-day fish assemblages subsequent to major physical alterations to waterways in the basin (Fagan et al. 2002, Olden and Poff 2005). Fish taxonomy followed Minckley and Marsh (2009) such that records of hybrids were discarded and unrecognized subspecies were grouped with the higher-level species designation. We also excluded fish records of reintroductions and from artificial ponds.

Conservation planning exercises require spatially extensive information on species distributions, based typically on both observed and modeled data (Elith et al. 2006). Regardless of the quality and quantity of available data, point location data are usually sparse geographically, can include errors of omission (falsely implying that a species is absent), and are often biased in their sampling toward areas that are easily accessible or of management/research interest. Therefore, we used species distribution models, specifically a nonlinear regression procedure known as multivariate adaptive regression splines (MARS [Friedman 1991]), to supplement observed sampling data. This method was selected based on its ability to incorporate data from multiple species to inform model development for data-poor species (i.e., a multi-response model [Elith et al. 2006]).

Our database includes records from museum specimens and single-species sampling efforts, which violated the assumptions of the MARS multi-response method (Elith et al. 2006). Thus, we only included records where at least two species had been observed, assuming that these indicated community sampling efforts $(n=1924$ catchments, where a catchment is the land that contributes to each stream segment). We acknowledge that not all of the sites included in our analysis may have been sampled for the entire fish fauna; however, it is not 
unexpected that many sites may have very few species given the low diversity that generally characterizes streams of the Lower Colorado River Basin (Pool et al. 2010). All MARS models were fitted in $R$ ( $R$ Development Core Team 2010) and utilized functions in the mda library, following Leathwick et al. (2005), who modified the algorithm to incorporate binomial error terms for presence/absence data as a generalized linear model. We modeled species occurrence in each catchment as a function of 23 predictor variables describing watershed hydrology, land use, regional climate, geology, and historical biogeography at different spatial scales (see Appendix A). These variables were selected based on their demonstrated importance in shaping patterns of fish species occurrence in the region (Pool et al. 2010). The predictive performance of models was evaluated using area under the Receiver Operating Characteristic curve (AUC [Fielding and Bell 1997]), which was calculated using 10-fold cross-validation. We considered an AUC $\geq 0.75$ as indicative of a useful model (Pearce and Ferrier 2000).

Using the outputs from MARS models, we generated separate raster layers for each of the native species for which we had sufficient occurrence records $(\geq 28$ occurrences) to model distributions in the Lower Colorado River Basin $(n=18)$ (Table 1). Models generated probability of occurrence for each species in each catchment of the basin; these were converted to raster grids at $1-\mathrm{km}^{2}$ resolution. Additionally, we were able to use point occurrence data for 22 native species that we could not model because of insufficient records $(<28$ occurrences; Table 1$)$. Some of these native species have been reduced to a small number of locations; including them in the conservation prioritization as point occurrences highlights the unique contribution of the taxa to taxonomic diversity. Distribution models were also generated for 21 nonnative species (Appendix B); probability of occurrence values were converted to presence or absence (decision threshold $=0.5$ ) and then summed to generate a nonnative fish richness value for each catchment. Additionally, records of nonnative species that could not be modeled were added to the richness value (Appendix B), which was also converted to a raster at $1-\mathrm{km}^{2}$ resolution.

\section{Conservation prioritization}

We evaluated and prioritized areas of high potential conservation value using the conservation program Zonation v.2.0 (Moilanen et al. 2009). The Zonation algorithm iteratively removed the $1-\mathrm{km}^{2}$ cells from the landscape that resulted in the smallest loss of conservation value, and was terminated when there were no cells remaining on the landscape. We chose to incorporate longitudinal connectivity (i.e., connections between upstream and downstream catchments) in the prioritization process by applying a recent module developed specifically for freshwater river systems (Moilanen et al. 2008). We used the National Hydrography Dataset
(United States Geological Survey 2004b) to delineate stream segments in the Lower Colorado River Basin, and the National Elevation Dataset (United States Geological Survey 2004a) to derive catchment boundaries (defined here as area of land contributing to a stream segment). We generated a set of unique identifiers for all catchments; these values were then used to create a raster that mapped out the physical location of all the catchments (Moilanen and Kujala 2008). Each catchment containing a large dam (e.g., $>1.83 \mathrm{~m}$ [Paukert et al. 2011]) was manually bisected based on the dam's location to account for the fragmenting effect on hydrologic connectivity; a catchment downstream of a dam is analogous to a headwater catchment. This module has proven successful at selecting longitudinally contiguous river basins and headwaters, as opposed to isolated catchments with high conservation value (Moilanen et al. 2008). Further details on the Zonation site prioritization are in Appendix C.

Our systematic conservation prioritization assessed multiple biodiversity values describing fish taxonomic, functional, and phylogenetic diversity. Although summary measures of diversity, such as richness or indices of functional and phylogenetic diversity, provide important information with which to compare sites, they fail to address complementarity, which is considered the foundation of modern systematic conservation planning (Margules and Pressey 2000, Linke et al. 2011). Thus, each of our diversity metrics constitutes multiple input layers that uniquely describe a particular species, trait, or phylogenetic relationship.

Taxonomic diversity was assessed by using native species probability of occurrence values predicted from the MARS species distribution models. Functional diversity was represented by a catchment $\times$ trait matrix, which was calculated by multiplying a species $\times$ trait matrix by a catchment $\times$ species matrix. We used a set of biological traits for the Colorado River Basin (Olden et al. 2006) describing the major ecological strategies exhibited by fishes in this region: egg size, maximum body length, total fecundity, relative age at maturation, reproductive guild, and trophic feeding guild (details in Appendix D). The species $\times$ trait matrix was filled with binary presence or absence values ( 1 if a species displays a trait state, 0 if not) for categorical variables. Each continuous trait was converted into three categorical trait states by taking the 33 rd and 67 th percentile of all continuous values, and assigning species to each category (e.g., the $33 \mathrm{rd}$ and 67 th percentiles for egg size were 1.9 and $2.1 \mathrm{~mm}$, respectively; all species $<1.9 \mathrm{~mm}$ were placed into the small-egg category and so forth; Appendix D). The catchment $\times$ species matrix contained species presence or absence derived from our species distribution models, in which we considered all species with probability of occurrence $\geq 0.5$ to be present. In the catchment $\times$ trait matrix, each cell represents the number of species in a watershed exhibiting a particular trait state. 

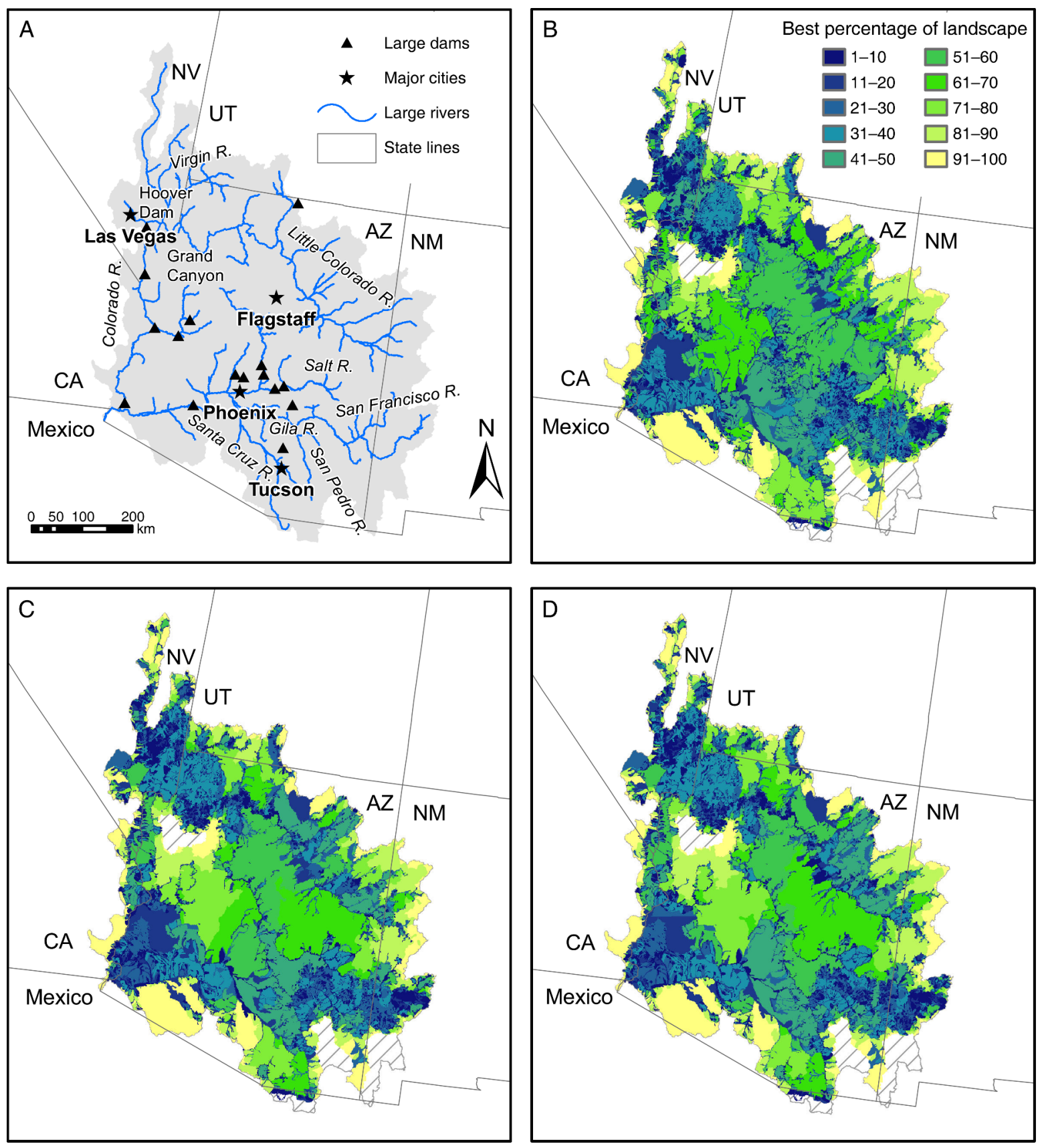

FIG. 1. Map and conservation prioritization of the Lower Colorado River Basin. (A) A map of the basin showing major cities, dams, and rivers; and conservation rankings of (B) taxonomic diversity; (C) functional diversity; and (D) phylogenetic diversity. In panels (B)-(D), the highest conservation priorities are indicated with the smallest values (i.e., $0.1-10$ is the best $10 \%$ of the landscape). Hatched areas represent closed catchments.

Phylogenetic diversity was calculated by constructing a catchment $\times$ node matrix (i.e., node in a phylogeny), similar to the methodology of Rodrigues and Gaston (2002). We used the qualitative phylogeny reported in Olden et al. (2008). Given that a robust phylogeny for desert fishes with quantitative branch lengths is not yet available and phylogenetic resolution can influence the calculation of phylogenetic diversity (Swenson 2009), we view this approach as being the most appropriate. First, each node in the phylogeny was assigned a unique identifier. From this, a species $\times$ node matrix was constructed, where each node is assigned a binary presence or absence if a species is ancestrally derived from this breakpoint. Thus, all species would be assigned a 1 for the most ancestral node. Finally, the species $X$ node matrix was multiplied by the catchment $X$ 
TABLE 1. Native fish species that were modeled with multivariate adaptive regression splines (MARS [Friedman 1991]), as well as species included as point occurrences in the program Zonation v. 2.0 (Moilanen et al. 2009).

\begin{tabular}{|c|c|c|c|c|c|c|}
\hline Scientific name & Common name & Family & Endemic & Federal status $\dagger$ & Zonation & AUC \\
\hline Agosia chrysogaster & longfin dace & Cyprinidae & NE & NL & model & 0.92 \\
\hline Catostomus clarkii & desert sucker & Catostomidae & LCRB & $\mathrm{SC}$ & model & 0.88 \\
\hline Catostomus discobolus & bluehead sucker & Catostomidae & CRB & NL & model & 0.96 \\
\hline Catostomus discobolus yarrowi & Zuni bluehead sucker & Catostomidae & LCRB & $\mathrm{C}$ & occurrences & na \\
\hline Catostomus insignis & Sonora sucker & Catostomidae & LCRB & $\mathrm{SC}$ & model & 0.91 \\
\hline Catostomus latipinnis & flannelmouth sucker & Catostomidae & $\mathrm{CRB}$ & $\mathrm{SC}$ & model & 0.98 \\
\hline Catostomus platyrhynchus & mountain sucker & Catostomidae & CRB & NL & occurrences & na \\
\hline Catostomus sp. & Little Colorado sucker & Catostomidae & LCRB & NL & model & na \\
\hline Cyprinodon macularius & desert pupfish & Cyprinodontidae & LCRB & $\mathrm{E}$ & model & 0.88 \\
\hline Gila cypha & humpback chub & Cyprinidae & $\mathrm{CRB}$ & E & model & 0.97 \\
\hline Gila elegans & bonytail chub & Cyprinidae & CRB & $\mathrm{E}$ & occurrences & na \\
\hline Gila intermedia & Gila chub & Cyprinidae & LCRB & E & model & 0.93 \\
\hline Gila nigra & headwater chub & Cyprinidae & LCRB & $\mathrm{C}$ & occurrences & na \\
\hline Gila robusta & roundtail chub & Cyprinidae & CRB & $\mathrm{C}$ & model & 0.86 \\
\hline Gila robusta jordani & Pahranagat roundtail chub & Cyprinidae & LCRB & E & occurrences & na \\
\hline Gila seminuda & Virgin River chub & Cyprinidae & LCRB & E & occurrences & na \\
\hline Lepidomeda albivallis & White River spinedace & Cyprinidae & LCRB & $\mathrm{E}$ & occurrences & na \\
\hline Lepidomeda mollispinis & Virgin spinedace & Cyprinidae & LCRB & RT & model & 0.95 \\
\hline Lepidomeda mollispinis pratensis & Big Spring spinedace & Cyprinidae & LCRB & $\mathrm{T}$ & occurrences & na \\
\hline Lepidomeda vittata & Little Colorado spinedace & Cyprinidae & LCRB & $\mathrm{T}$ & occurrences & na \\
\hline Meda fulgida & spikedace & Cyprinidae & LCRB & $\mathrm{T}$ & model & 0.94 \\
\hline Oncorhynchus gilae apache & Apache trout & Salmonidae & LCRB & $\mathrm{T}$ & model & 0.95 \\
\hline Oncorhynchus gilae gilae & Gila trout & Salmonidae & LCRB & $\mathrm{T}$ & occurrences & na \\
\hline Plagopterus argentissimus & woundfin & Cyprinidae & LCRB & E & occurrences & na \\
\hline Poeciliopsis occidentalis occidentalis & Gila topminnow & Poeciliidae & NE & E & model & 0.91 \\
\hline Ptychocheilus lucius & Colorado pikeminnow & Cyprinidae & CRB & E & model & 0.94 \\
\hline Rhinichthys cobitis & loach minnow & Cyprinidae & LCRB & $\mathrm{T}$ & model & 0.95 \\
\hline Rhinichthys osculus & speckled dace & Cyprinidae & NE & $\mathrm{SC} \ddagger$ & model & 0.84 \\
\hline Xyrauchen texanus & razorback sucker & Catostomidae & CRB & $\mathrm{E}$ & model & 0.85 \\
\hline
\end{tabular}

Notes: AUC refers to the area under the receiver operating characteristic curve. Note that an additional 11 native species were included as point occurrences $(n=12$ catchments) in taxonomic diversity scenarios, but the lack of functional or phylogenetic information precluded usage in functional and phylogenetic scenarios. LCRB means endemic to Lower Colorado Basin, CRB means endemic to Colorado Basin, NE means not endemic (Carlson and Muth 1989, Olden et al. 2008). In the last column, na is "not applicable."

$\dagger$ Listing under the Endangered Species Act: E, endangered; T, threatened; C, candidate; SC, species of concern; NL, not listed; $\mathrm{RT}$, resolved taxon.

$\$$ There are a number of subspecies of Rhinichthys osculus that could not be distinguished in our database; federal status ranges from endangered to species of concern.

species matrix to generate the catchment $\times$ node matrix, where each cell represents the number of species in a watershed containing a 1 for the node. In order to most closely match the native species list used in the taxonomic diversity evaluation, we included species that lacked trait and phylogenetic information by assigning values of the most closely related species (within the same genera).

To account for the ecological effects of nonnative species on native species in the study region, we used a feature of Zonation that allows explicit connectivity between different input layers (i.e., native vs. nonnative species). This feature was originally designed to model the positive effect of spatial proximity between consumer and resource (Rayfield et al. 2009); here, we apply it to incorporate the negative interaction between nonnative and native species. In this case, the algorithm returns lower priority to those catchments with higher nonnative richness.

Our conservation prioritization considered the effect of contemporary and future threats on the probability of persistence of native species. We used a multi-metric anthropogenic threat index describing landscape-level threats of land use (e.g., agriculture), waterway development and diversions (e.g., number of dams), and human development (e.g., road density) developed for the Lower Colorado River Basin (Paukert et al. 2011). Threat values were used to weight the probability of occurrence values of each species (Appendix E). For example, in a catchment with a high anthropogenic threat index value, input values of species probabilities of occurrence in that region would be suitably downweighted to account for the greater uncertainty of a species occurrence (Moilanen et al. 2009). This method selects areas with both high conservation value and low contemporary threat indicating high likelihood for species persistence (Moilanen et al. 2009).

\section{Analysis}

Our conservation prioritization yielded a ranking from $0.1 \%$ to $100 \%$ for all of the catchments on the landscape, where lower values represent the highest conservation priorities (i.e., a catchment with a conservation value of 1 is ranked among the best $1 \%$ of the landscape). We assessed congruence between the results of conservation prioritizations with different measures 
of diversity by comparing the spatial concordance between the top $10 \%$ and at successive $10 \%$ intervals for all pairwise combinations of diversity measures, as well as simultaneously considering all three diversity measures. In order to determine whether congruence was greater than that which would occur at random, we performed a randomization procedure with $n=999$ permutations in R ( $\mathrm{R}$ Development Core Team 2010).

Conservation rankings were then compared to contemporary maps of protected areas, nonnative species richness, and the anthropogenic threat index, as well as future projections of impervious surface cover and climate change. Although nonnative species and the anthropogenic threat index were explicitly included in the optimization algorithm, we assessed the congruence of these contemporary threats with conservation priority rankings in order to determine how influential these variables were in the prioritization process. Areas were considered protected if they fell into GAP class 1, describing permanent protection from conversion of natural land cover with natural disturbance regimes (Sowa et al. 2007) (Appendix E). Projections of changes to impervious surface cover in catchments were performed in ArcGIS using the ICLUS v1.2 tool (United States Environmental Protection Agency 2009a). This tool utilizes the Intergovernmental Panel on Climate Change social, economic, and demographic storylines to model changes in human population size and distribution across the United States (Intergovernmental Panel on Climate Change 2007). Changes in impervious surface were derived from projections of human population density and housing density for emission scenario A2 between the years 2010 and 2100 (Appendix E). Temperature and precipitation projections were based on a multi-model ensemble of 16 General Circulation Models for emission scenario A2 (Intergovernmental Panel on Climate Change 2007) for the years 2070-2099 (median value of the first model run) using downscaled projections obtained from Climate Wizard (Girvetz et al. 2009) (Appendix E).

For the analysis of congruence between regions of potential conservation priority and contemporary and future threats we selected areas in the top 20th percentile of nonnative species richness, anthropogenic threats, future change in temperature, and future change in impervious surface as conservative estimates of the degree of congruence with conservation priorities. For precipitation, we selected the top 10th and bottom 90th percentile of future projected changes, as we might expect that both wet and dry extremes will present conservation challenges.

\section{RESUlts}

Priority rankings for areas with high taxonomic, functional, and phylogenetic conservation value are depicted by a spatial mosaic of river systems distributed across the Lower Colorado River Basin (Fig. 1). River basins represented by contiguous areas of high conser-

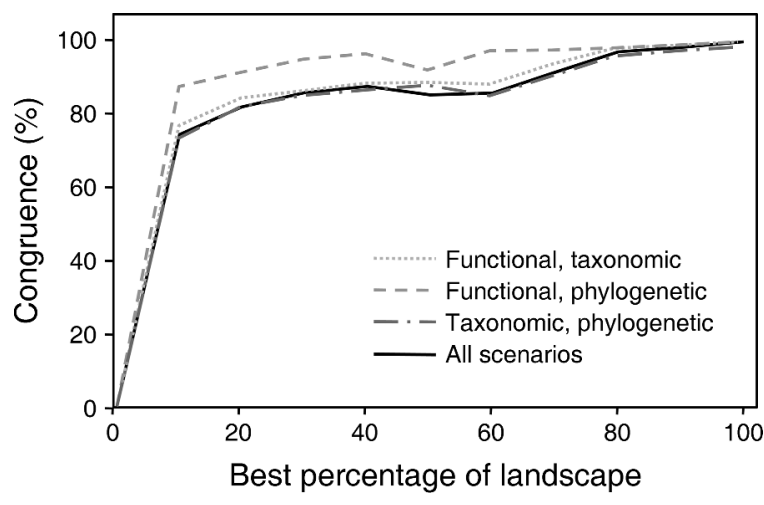

FIG. 2. Congruence (\%) between the output of different conservation scenarios for measures of species diversity along a gradient of increasing cumulative fractions of landscape quality. For example, the best $10 \%$ of the landscape for functional and phylogenetic diversity results in $88 \%$ congruence between scenarios.

vation value included the Virgin, Little Colorado (lower reaches), Gila (upper reaches), Verde, Salt (upper reaches), Santa Cruz, and the San Pedro Rivers for individual diversity scenarios (Fig. 1), as well as averaged across all scenarios (Appendix F). For the highest ranking $10 \%$ of each diversity scenario (i.e., the area of the landscape representing the best $10 \%$ ), the highest congruence was between the functional and phylogenetic diversity scenarios (88\%), and the lowest congruence was between phylogenetic diversity and taxonomic diversity (75\%) (Fig. 2). When all three scenarios were compared simultaneously, congruence was $75 \%$ for the highest ranking $10 \%$ of each scenario (Fig. 2). All combinations of diversity scenarios were significantly more congruent than random expectations $(n=999$ permutations; $P<0.001)$.

Further, we examined pairwise patterns of spatial mismatch for taxonomic, functional, and phylogenetic diversity scenarios (Fig. 3). The Grand Canyon reach of the Colorado River from the confluence with the Little Colorado River downstream to the Hoover Dam was highly ranked for all diversity scenarios; however, the region around and just upstream of Hoover Dam was more highly ranked for taxonomic diversity compared to functional and phylogenetic diversity (Fig. 3). Higher rankings for taxonomic diversity compared to functional and phylogenetic diversity were also observed through the middle of the basin, including catchments around the Salt and Verde Rivers (Fig. 3). Portions of the Little Colorado River Basin, the main stem Colorado River downstream of the Hoover Dam, and the headwaters of the Gila River and San Francisco River were ranked more highly for functional and phylogenetic diversity compared to taxonomic diversity (Fig. 3).

As nonnative species are known to significantly affect the distribution of native fish species in the Lower Colorado River Basin, we contrasted the taxonomic diversity scenario with and without interactions with 

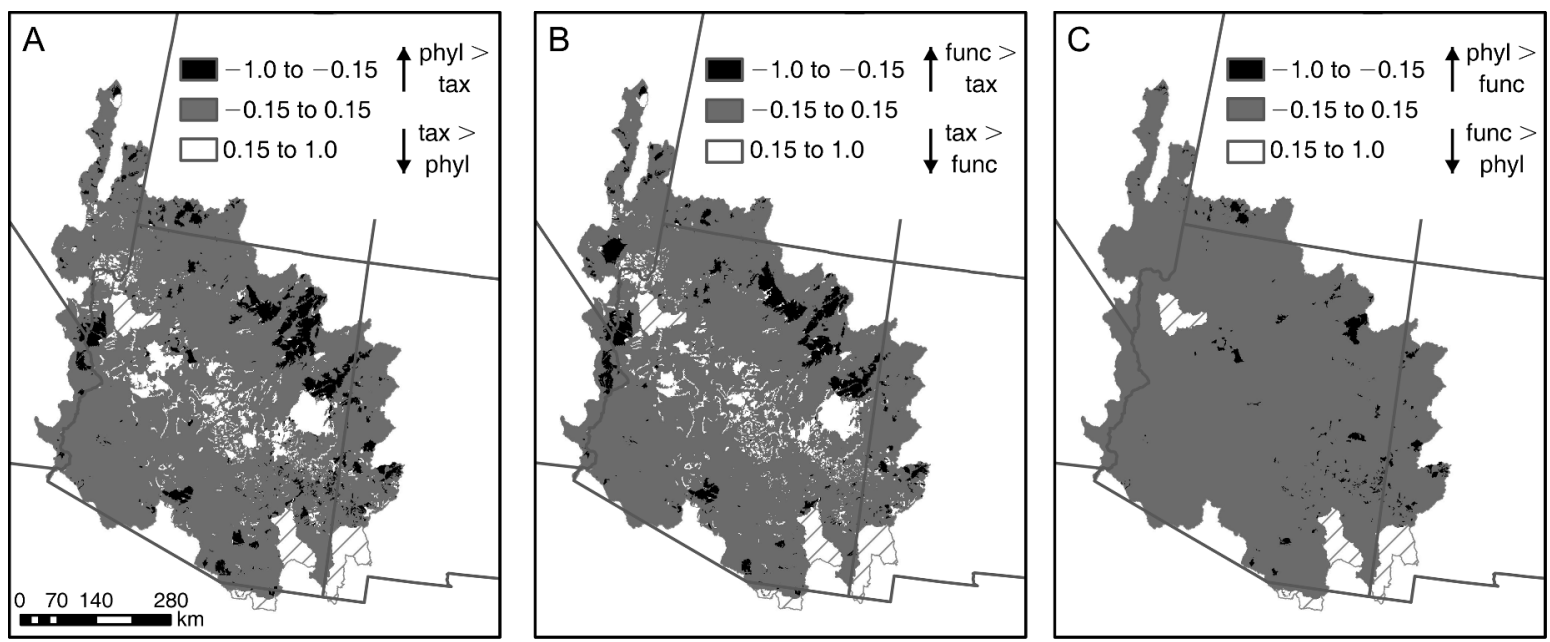

FIG. 3. Spatial mismatches between (A) taxonomic-phylogenetic, (B) taxonomic-functional, and (C) functional-phylogenetic conservation scenario priority rankings. Hatched areas represent closed catchments. Abbreviations: tax, taxonomic; phyl, phylogenetic; func, functional.

nonnative species to assess the importance of biotic interactions on the selection of priority conservation areas. These interactions consider the competitive and predatory effects of nonnative fishes on native fishes, and therefore, attempt to minimize regions of spatial overlap between them. There was a high degree of congruence (99\%) between the top $10 \%$ of both scenarios (based on area); however, including interaction terms in the selection algorithm resulted in a $16 \%$ increase in area required to protect one-tenth of all native species taxonomic diversity (based on representativeness).

Congruence between the top $10 \%$ of conservation priorities and regions of high nonnative species richness and threats to biodiversity were generally low, ranging from $13 \%$ to $23 \%$ and from $14 \%$ to $25 \%$, respectively, for different biodiversity scenarios (Fig. 4; Appendix E). Although we purposely constrained the analyses to place lower priority on areas with a large number of nonnative species and high contemporary threats (see Materials and methods), this illustrates the trade-offs that challenge the conservation of native species in the Lower Colorado River Basin, in that there are few regions on the landscape where these threats have not yet penetrated. Different conservation scenarios were relatively incongruent with catchments that currently have protected status: $14-15 \%$ of the top $10 \%$ of conservation priorities were in lands classified as having permanent protection from conversion of natural land cover with a natural disturbance regime (i.e., GAP 1 [Sowa et al. 2007]) (Fig. 4). Additionally, 20-24\% were in lands with a lower protection status, classified as having permanent protection from conversion of natural land cover with a managed disturbance regime (i.e., GAP 2 [Sowa et al. 2007]) (Appendix E).

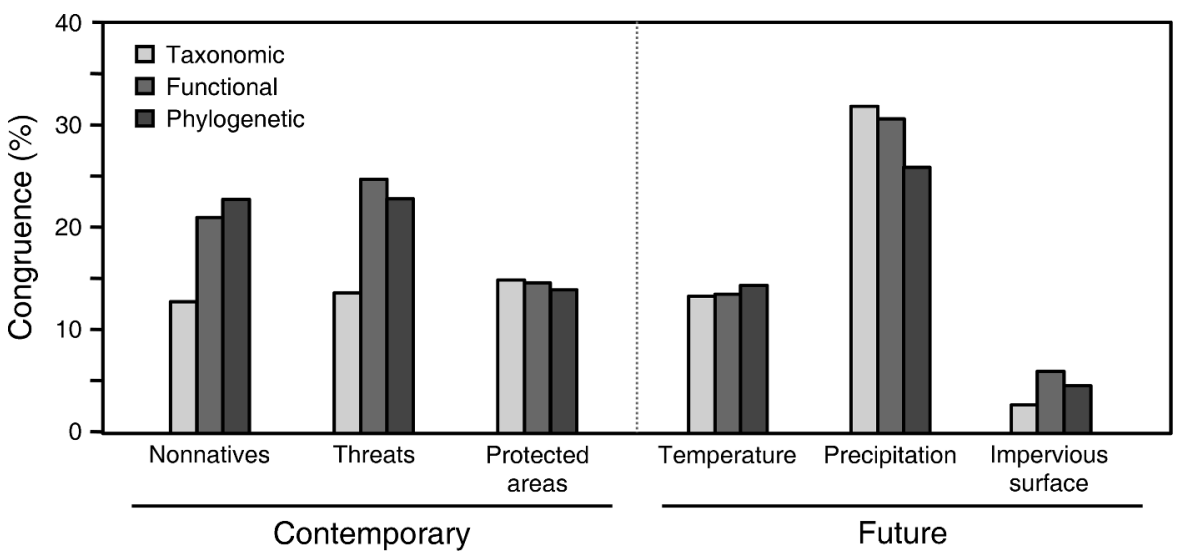

FIG. 4. Congruence (\%) between the top $10 \%$ of different conservation scenarios with contemporary nonnative species richness (top 20th percentile), multi-parameter threat index (top 20th percentile), protected areas (GAP classification 1); and between future projected changes in temperature (top 20th percentile), precipitation (top 10th and bottom 90th percentile), and impervious surface (top 20th percentile). 
The entire Lower Colorado River Basin is predicted to become warmer by the year 2100; therefore, the highest conservation priorities fall in regions where temperatures are projected to increase by at least 10-14\% (Appendix $\mathrm{G})$. The top conservation priorities were $14-15 \%$ congruent with regions of the most extreme temperature increases associated with projected climate change (14$18 \%$ increase; Fig. 4; Appendix E). The highest conservation priority lands were $26-32 \%$ congruent with regions that are predicted to experience the greatest changes in precipitation by the year 2100 (Fig. 4, Appendix E). Most of these conservation priorities are located in areas where precipitation is projected to decrease by up to $13 \%$ (Appendix G). Although population and housing density is predicted to increase substantially in the American Southwest in the coming century (United States Environmental Protection Agency 2009b), there was little congruence between the best $10 \%$ of conservation scenarios and regions with the greatest projected changes in impervious surface (3-6\%; Fig. 4; Appendix E). In general, high conservation priority catchments fall in regions predicted to experience small increases in impervious surface (Appendix G).

\section{DisCuSSION}

Using newly developed systematic conservation prioritization techniques, our study provides the first systematic prioritization for freshwaters that incorporates multiple conservation values describing fish taxonomic, functional, and phylogenetic diversity. These results have utility from both an applied and an ecological perspective, describing regions where conservation efforts should optimally be allocated and ecological differences resulting from the use of several diversity measures. We found that efforts to conserve endangered freshwater fishes in the Lower Colorado River Basin will be met with a number of opportunities, trade-offs, and challenges.

\section{Opportunities}

One of the most striking results was the level of concordance between different measures of diversity: the top $10 \%$ of the landscape was congruent for $75 \%$ of catchments across measures of taxonomic, functional, and phylogenetic diversity (Fig. 2). These conservation priorities were not merely the most diverse parts of the landscape, but rather, form a comprehensive network in which all species, functional groups, and phylogenetic histories are represented. However, we found that less than one-fifth of the top conservation priorities are currently within the highest class of protected areas. By contrast, Esselman and Allan (2011) found that more than half of the conservation priorities for native fishes of Belize were located in protected areas. This suggests that there is significant opportunity to feasibly expand current protected areas and simultaneously protect three major dimensions of biodiversity. Additionally, there is great potential to utilize information on priority incongruities to highlight regions of contrasting diversities of taxonomy, function, and phylogeny that may indicate unique ecological and evolutionary processes that are critical for watershed conservation.

Although studies have increasingly identified the need for conservation at the scale of the landscape (Brooks et al. 2006), conservation efforts are typically focused at more localized spatial scales (e.g., a tributary or headwater stream). The systematic conservation approach used in our study allows for the identification of localized priority catchments, which can be targeted for smaller-scale conservation efforts. For example, conservation and restoration in a $15-\mathrm{km}$ stretch of Fossil Creek, Arizona resulted in significant increases in native fish abundance (Marks et al. 2010); our study identified the upper portions of Fossil Creek as high conservation priority, with some stream segments in the top $1 \%$ of the entire basin (A. L. Strecker, unpublished data). Thus, our study presents an opportunity to bridge the "researchimplementation" gap (Knight et al. 2008) by meeting the needs of conservation practitioners (i.e., matching the scale of the conservation plan to the most realistic scale for implementation), as well as making the results readily available for viewing in Google Earth (Supplement) (J. D. Olden, unpublished data).

\section{Trade-offs}

Efforts to conserve imperiled species must contend with a number of trade-offs. Spatial incongruities in regions of high taxonomic, functional, and/or phylogenetic diversity have been observed previously in terrestrial communities (Devictor et al. 2010). One-quarter of the top conservation priorities were incongruent across different facets of diversity in our study of riverine freshwater ecosystems, suggesting that divergence of taxonomic, functional, and phylogenetic diversity may be a general property of communities. This incongruence may be due to a number of factors, such as negative interactions between functionally similar species within lineages reducing functional diversity relative to phylogenetic diversity (Prinzing et al. 2008), environmental factors independently altering different diversity components (Webb et al. 2002), and clumped occupation of niche space altering taxonomic diversity relative to functional diversity (Díaz and Cabido 2001). Fishes in the American Southwest have evolved under extremely dynamic physical conditions and an active geological history, resulting in a highly endemic fauna with unique adaptations (Lytle and Poff 2004). However, this taxonomic diversity has not necessarily been reflected in patterns of functional diversity. Many native fishes have converged on a bet-hedging strategy that reflects a fundamental trade-off between the timing of maturation and reproductive output, which is considered adaptive in highly unpredictable environments (Olden et al. 2006). As well, there is some evidence of phylogenetic clumping (Faith and Baker 2006), whereby the loss of species from certain locales would result in disproportionately greater 
losses in phylogenetic diversity compared to taxonomic diversity (e.g., the highly diverged endemic Oncorhynchus spp.).

It was not unexpected that we observed relatively high congruence between comparisons of taxonomic-functional or taxonomic-phylogenetic diversity: increasing taxonomic diversity will promote greater functional and phylogenetic diversity depending on the degree of redundancy. Micheli and Halpern (2005) hypothesized that the relationship between taxonomic and functional diversity could take different forms (e.g., low functional redundancy, high redundancy, asymptotic functional diversity). Therefore, this is an additional factor that will influence the degree of concordance between taxonomic and functional conservation priorities. Additionally, the spatial incongruities that were observed between diversity scenarios (Fig. 3), as well as differences in the degree of overlap of contemporary threats with different diversity measures (Fig. 4), both suggest that there is variation in the types of functions and phylogenetic histories that result from unique species combinations, which cannot wholly be explained by examining taxonomic richness. Indeed, $>40000 \mathrm{~km}^{2}$ of the Lower Colorado River Basin diverges in functional or phylogenetic prioritization values by $>15 \%$ from taxonomic priority values.

Our results suggest that the consequences of species loss are more severe for functional and phylogenetic diversity, which decline at a slightly steeper rate as land units are removed from conservation scenarios (Appendix H). Additionally, functional and phylogenetic conservation priorities exhibit substantially greater overlap with nonnative species distributions and anthropogenic threats compared to taxonomic diversity (Fig. 4). This suggests that hotspots of functional and phylogenetic diversity are at greater risk from landscape-scale biotic and abiotic threats. Thus, we have demonstrated that consideration of taxonomic diversity alone may not provide adequate representation for all types of diversity in systematic conservation prioritizations, requiring a greater emphasis on identifying key watersheds that contribute disproportionately to basinwide functional and phylogenetic diversity. This is an important finding with regard to conserving multiple dimensions of biodiversity, and should be a consideration in future systematic conservation planning studies; however, we recognize that functional and phylogenetic data on species are rarely available across an entire ecosystem, making assessments of this nature difficult to obtain. Given these data limitations, taxonomic diversity may represent an adequate surrogate for conservation of multiple aspects of biodiversity.

In addition to weighting conservation priorities among different aspects of diversity, conservation of threatened species must also address trade-offs within measures of diversity. For instance, conservationists are challenged to allocate resources between highly endangered rare species and species that are more common, but still threatened (Sowa et al. 2007). Ideally, conservation and management strategies would simultaneously protect all species; however, actions that are targeted toward one threatened species may be detrimental to another (Simberloff 1998). In our analysis of conservation priorities for taxonomic diversity, all species were given equal weight; however, we also analyzed a scenario where fish species were assigned priority rankings based on recommendations of the Desert Fish Habitat Partnership (2008), which used expert opinions based on endemism, cross-jurisdictional cooperation, federal listing, population status, and management needs to rank species. Under this alternative scenario, there was extremely high concordance (99\%) in regions identified as top conservation priorities in comparison with the unranked taxonomic diversity scenario (A. L. Strecker, unpublished data). This suggests that trade-offs between spatial priorities for different fish species of the American Southwest are minor.

\section{Challenges}

There are significant contemporary challenges that face conservation of endangered fishes in the American Southwest. Traditionally, the goal of conservation planning was to protect pristine habitats and diverse native populations (Margules and Pressey 2000), but the reality for native biota of the arid Southwest is that preserving biodiversity will be complicated by a vast array of threats that are pervasive across the landscape (Paukert et al. 2011). Our results demonstrate that up to a quarter of the best $10 \%$ of landscape priorities fall in catchments that have high numbers of nonnative species and high contemporary anthropogenic threats (Fig. 4). In large part, the challenge in protecting riverine ecosystems reflects the continuous nature of the system. For example, disturbances originating upstream can have a substantial influence on catchments downstream (e.g., agriculture [Allan 2004]) and nonnative species introduced at a point source can spread rapidly upstream and downstream (Eby et al. 2003, Olden and Poff 2005). This challenge has led to calls for integrated catchment management strategies, which include protection of specific freshwater features (e.g., spawning areas), and management of upstream catchments that are critical to its functionality (e.g., migration corridors, riparian buffers) (Abell et al. 2007, Linke et al. 2011). Indeed, understanding the effects of current and future management scenarios is a promising new direction for systematic conservation planning in freshwaters (Turak et al. 2011). Our results point to those watersheds that are the most important for their contribution to basinwide representation of biological diversity and suggest that conservation of native fish species may need to consider mitigation of threats and intensive management of nonnative species, particularly in restricting stocking or spread of nonnative game fish species into areas representing critical sources of taxonomic, functional and phylogenetic diversity. 
A further challenge comes in the evaluation of conservation targets. It is important to note that freshwater ecosystems in the American Southwest are generally species poor, such that increases in any measure of diversity may not represent a conservation success, but rather reflect biological responses to altered abiotic or biotic conditions. It is now recognized that assessing the adequacy of conservation targets requires a greater understanding of the processes that drive species persistence as well as species habitat and resource needs (Linke et al. 2011). This type of approach was employed in the study of Leathwick et al. (2010), which linked landscape patterns of biodiversity to environmental conditions, using dissimilarities between environmental classes as targets for conservation. We suggest that the "biologically informed physical surrogate" approach of Leathwick et al. (2010) is complementary to our use of "biological surrogate" targets for biodiversity (sensu Linke et al. 2011), as both approaches can inform the effective conservation of species and habitats.

Finally, conservation planning for the arid Southwest will be met with challenges in the coming decades. While climate-induced range shifts of species have been considered in terrestrial conservation planning studies for several decades (Peters and Darling 1985), they have received little attention in freshwater protected areas. We have demonstrated that conservation efforts across the entire Lower Colorado River Basin must contend with increased temperature $\left(3-4^{\circ} \mathrm{C}\right.$ by 2100$)$ and changes in precipitation, including greater aridity in much of the basin (declines of up to $13 \%$ ), as well as the possibility of increased precipitation in some regions $(>11 \%)$, likely during the monsoon season (Mitchell et al. 2002). These climatic changes pose a significant hurdle for conserving freshwater fishes in the region, as fish are generally constrained to waterways and have poor dispersal ability. Under these circumstances, the primary options to protect native fishes may be to maintain thermal refugia and dispersal corridors (Abell et al. 2007) or consider more controversial approaches such as assisted colonization (Olden et al. 2011). Additionally, phylogenetic diversity represents the diversity of different features in assemblages, which maximizes the chances that a species will have the right feature to respond to future changes (Forest et al. 2007). Thus, the ability of native fish assemblages to respond to future abiotic conditions will be compromised by the loss of phylogenetic diversity. Our analysis shows that phylogenetic diversity is the least well-represented aspect of diversity in current reserve areas, and may need to be considered a priority for conservation and management in the Lower Colorado River Basin.

\section{CONCLUSIONS}

Utilizing information on multiple aspects of diversity maximizes future options, and allows managers and conservationists to systematically conserve areas at the appropriate spatial scales (Brooks et al. 2006). Our results generate insight into ecological and applied conservation science in underserved freshwater biomes, and highlights areas for future research, including a greater understanding of the processes that generate and maintain dimensions of biodiversity. Conservation approaches that integrate contemporary and future threats, interactions with nonnative species, and multiple aspects of diversity will better inform conservation of imperiled native fish assemblages.

\section{ACKNOWLEDGMENTS}

We thank P. Angermeier, D. Magoulick, H. Kujala, D. Lawrence, T. Pool, and two anonymous reviewers for constructive feedback. Funding was provided by the USGS Status and Trends Program and the USGS National Gap Analysis Program. We thank the Desert Fish Habitat Partnership for input and comments on this research. The use of trade, product, industry names or products does not constitute an endorsement by the U.S. Government, the U.S. Geological Survey, or other sponsoring or participating agencies. The Missouri Cooperative Fish and Wildlife Research Unit is sponsored by the Missouri Department of Conservation, the University of Missouri, the U.S. Fish and Wildlife Service, the U.S. Geological Survey, and the Wildlife Management Institute.

\section{Literature Cited}

Abell, R., J. D. Allan, and B. Lehner. 2007. Unlocking the potential of protected areas for freshwaters. Biological Conservation 134:48-63.

Allan, J. D. 2004. Landscapes and riverscapes: the influence of land use on stream ecosystems. Annual Review of Ecology Evolution and Systematics 35:257-284.

Barmuta, L. A., S. Linke, and E. Turak. 2011. Bridging the gap between 'planning' and 'doing' for biodiversity conservation in freshwaters. Freshwater Biology 56:180-195.

Brooks, T. M., R. A. Mittermeier, G. A. B. da Fonseca, J. Gerlach, M. Hoffmann, J. F. Lamoreux, C. G. Mittermeier, J. D. Pilgrim, and A. S. L. Rodrigues. 2006. Global biodiversity conservation priorities. Science 313:58-61.

Carlson, C. A., and R. T. Muth. 1989. The Colorado River: lifeline of the American Southwest. Pages 220-239 in D. P. Dodge, editor. Proceedings of the International Large River Symposium. Canadian Special Publications in Fisheries and Aquatic Sciences 106, Ottawa, Ontario, Canada.

Cumming, G. S., and M. F. Child. 2009. Contrasting spatial patterns of taxonomic and functional richness offer insights into potential loss of ecosystem services. Philosophical Transactions of the Royal Society B 364:1683-1692.

Desert Fish Habitat Partnership. 2008. Framework for strategic conservation of desert fishes. Desert Fish Habitat Partnership Workgroup 〈http://www.nature.nps.gov/water/ Fisheries_Partnership/Documents/ $\rangle$

Devictor, V., D. Mouillot, C. Meynard, F. Jiguet, W. Thuiller, and N. Mouquet. 2010. Spatial mismatch and congruence between taxonomic, phylogenetic and functional diversity: the need for integrative conservation strategies in a changing world. Ecology Letters 13:1030-1040.

Díaz, S., and M. Cabido. 2001. Vive la différence: plant functional diversity matters to ecosystem processes. Trends in Ecology and Evolution 16:646-655.

Eby, L. A., W. F. Fagan, and W. L. Minckley. 2003. Variability and dynamics of a desert stream community. Ecological Applications 13:1566-1579.

Elith, J., et al. 2006. Novel methods improve prediction of species' distributions from occurrence data. Ecography 29:129-151. 
Esselman, P. C., and J. D. Allan. 2011. Application of species distribution models and conservation planning software to the design of a reserve network for the riverine fishes of northeastern Mesoamerica. Freshwater Biology 56:71-88.

Fagan, W. F., P. J. Unmack, C. Burgess, and W. L. Minckley. 2002. Rarity, fragmentation, and extinction risk in desert fishes. Ecology 83:3250-3256.

Faith, D. P. 1992. Conservation evaluation and phylogenetic diversity. Biological Conservation 61:1-10.

Faith, D. P., and A. M. Baker. 2006. Phylogenetic diversity (PD) and biodiversity conservation: some bioinformatics challenges. Evolutionary Bioinformatics 2:121-128.

Fielding, A. H., and J. F. Bell. 1997. A review of methods for the assessment of prediction errors in conservation presence/ absence models. Environmental Conservation 24:38-49.

Forest, F., et al. 2007. Preserving the evolutionary potential of floras in biodiversity hotspots. Nature 445:757-760.

Friedman, J. H. 1991. Multivariate adaptive regression splines. Annals of Statistics 19:1-67.

Girvetz, E. H., C. Zganjar, G. T. Raber, E. P. Maurer, P. Kareiva, and J. J. Lawler. 2009. Applied climate-change analysis: the Climate Wizard tool. Plos One 4:e8320.

Hermoso, V., S. Linke, J. Prenda, and H. P. Possingham. 2011. Addressing longitudinal connectivity in the systematic conservation planning of fresh waters. Freshwater Biology 56:57-70.

Hooper, D. U., et al. 2005. Effects of biodiversity on ecosystem functioning: a consensus of current knowledge. Ecological Monographs 75:3-35.

Intergovernmental Panel on Climate Change. 2007. Climate change 2007: impacts, adaptation and vulnerability. Cambridge University Press, Cambridge, UK.

Klein, C., K. Wilson, M. Watts, J. Stein, S. Berry, J. Carwardine, M. S. Smith, B. Mackey, and H. Possingham. 2009. Incorporating ecological and evolutionary processes into continental-scale conservation planning. Ecological Applications 19:206-217.

Knight, A. T., R. M. Cowling, M. Rouget, A. Balmford, A. T. Lombard, and B. M. Campbell. 2008. Knowing but not doing: selecting priority conservation areas and the researchimplementation gap. Conservation Biology 22:610-617.

Leathwick, J. R., A. Moilanen, S. Ferrier, and K. Julian. 2010. Complementarity-based conservation prioritization using a community classification, and its application to riverine ecosystems. Biological Conservation 143:984-991.

Leathwick, J. R., D. Rowe, J. Richardson, J. Elith, and T. Hastie. 2005. Using multivariate adaptive regression splines to predict the distributions of New Zealand's freshwater diadromous fish. Freshwater Biology 50:2034-2052.

Leprieur, F., O. Beauchard, S. Blanchet, T. Oberdorff, and S. Brosse. 2008. Fish invasions in the world's river systems: when natural processes are blurred by human activities. PLoS Biology 6:e28.

Linke, S., E. Turak, and J. L. Nel. 2011. Freshwater conservation planning: the case for systematic approaches. Freshwater Biology 56:6-20.

Lytle, D. A., and N. L. Poff. 2004. Adaptation to natural flow regimes. Trends in Ecology and Evolution 19:94-100.

Margules, C. R., and R. L. Pressey. 2000. Systematic conservation planning. Nature 405:243-253.

Marks, J. C., G. A. Haden, M. O'Neill, and C. Pace. 2010. Effects of flow restoration and exotic species removal on recovery of native fish: lessons from a dam decommissioning. Restoration Ecology 18:934-943.

Micheli, F., and B. S. Halpern. 2005. Low functional redundancy in coastal marine assemblages. Ecology Letters 8:391-400.

Minckley, W. L., and P. C. Marsh. 2009. Inland fishes of the Greater Southwest: chronicle of a vanishing biota. University of Arizona Press, Tucson, Arizona, USA.
Mitchell, D. L., D. Ivanova, R. Rabin, T. J. Brown, and K. Redmond. 2002. Gulf of California sea surface temperatures and the North American monsoon: mechanistic implications from observations. Journal of Climate 15:2261-2281.

Moilanen, A., and H. Kujala. 2008. The Zonation conservation planning framework and software v.2.0: user manual. 〈www. helsinki.fi/BioScience/ConsPlan〉

Moilanen, A., H. Kujala, and J. Leathwick. 2009. The Zonation framework and software for conservation prioritization. Pages 196-210 in A. Moilanen, K. A. Wilson, and H. P. Possingham, editors. Spatial conservation prioritization: quantitative methods and computational tools. Oxford University Press, Oxford, UK.

Moilanen, A., J. Leathwick, and J. Elith. 2008. A method for spatial freshwater conservation prioritization. Freshwater Biology 53:577-592.

Nel, J. L., D. J. Roux, R. Abell, P. J. Ashton, R. M. Cowling, J. V. Higgins, M. Thieme, and J. H. Viers. 2009. Progress and challenges in freshwater conservation planning. Aquatic Conservation-Marine and Freshwater Ecosystems 19:474485.

Olden, J. D., M. J. Kennard, J. J. Lawler, and N. L. Poff. 2011. Challenges and opportunities in implementing managed relocation for conservation of freshwater species. Conservation Biology 25:40-47.

Olden, J. D., and N. L. Poff. 2005. Long-term trends of native and non-native fish faunas in the American Southwest. Animal Biodiversity and Conservation 28:75-89.

Olden, J. D., N. L. Poff, and K. R. Bestgen. 2006. Life-history strategies predict fish invasions and extirpations in the Colorado River Basin. Ecological Monographs 76:25-40.

Olden, J. D., N. L. Poff, and K. R. Bestgen. 2008. Trait synergisms and the rarity, extirpation, and extinction risk of desert fishes. Ecology 89:847-856.

Paukert, C. P., K. L. Pitts, J. B. Whittier, and J. D. Olden. 2011. Development and assessment of a landscape-scale ecological threat index for the Lower Colorado River Basin. Ecological Indicators 11:304-310.

Pearce, J., and S. Ferrier. 2000. Evaluating the predictive performance of habitat models developed using logistic regression. Ecological Modelling 133:225-245.

Peters, R. L., and J. D. S. Darling. 1985. The greenhouse effect and nature reserves. BioScience 35:707-717.

Pool, T. K., J. D. Olden, J. B. Whittier, and C. P. Paukert. 2010. Environmental drivers of fish functional diversity and composition in the Lower Colorado River Basin. Canadian Journal of Fisheries and Aquatic Sciences 67:1791-1807.

Pressey, R. L., M. Cabeza, M. E. Watts, R. M. Cowling, and K. A. Wilson. 2007. Conservation planning in a changing world. Trends in Ecology and Evolution 22:583-592.

Prinzing, A., R. Reiffers, W. G. Braakhekke, S. M. Hennekens, O. Tackenberg, W. A. Ozinga, J. H. J. Schaminee, and J. M. van Groenendael. 2008. Less lineages-more trait variation: phylogenetically clustered plant communities are functionally more diverse. Ecology Letters 11:809-819.

R Development Core Team. 2010. R: a language and environment for statistical computing. R Foundation for Statistical Computing, Vienna, Austria.

Rayfield, B., A. Moilanen, and M.-J. Fortin. 2009. Incorporating consumer-resource spatial interactions in reserve design. Ecological Modelling 220:725-733.

Rodrigues, A. S. L., and K. J. Gaston. 2002. Maximising phylogenetic diversity in the selection of networks of conservation areas. Biological Conservation 105:103-111.

Sabo, J. L., et al. 2010. Reclaiming freshwater sustainability in the Cadillac Desert. Proceedings of the National Academy of Sciences USA 107:21263-21269.

Simberloff, D. 1998. Flagships, umbrellas, and keystones: is single-species management passé in the landscape era? Biological Conservation 83:247-257. 
Sowa, S. P., G. Annis, M. E. Morey, and D. D. Diamond. 2007. A gap analysis and comprehensive conservation strategy for riverine ecosystems of Missouri. Ecological Monographs 77:301-334.

Swenson, N. G. 2009. Phylogenetic resolution and quantifying the phylogenetic diversity and dispersion of communities. PLos One 4:e4390.

Turak, E., S. Ferrier, T. Barrett, E. Mesley, M. Drielsma, G. Manion, G. Doyle, J. Stein, and G. Gordon. 2011. Planning for the persistence of river biodiversity: exploring alternative futures using process-based models. Freshwater Biology 56:39-56.

Turner, D. S., and M. D. List. 2006. Habitat mapping and conservation analysis to identify critical streams for Arizona's native fish. Aquatic Conservation: Marine and Freshwater Ecosystems 17:737-748.

United States Environmental Protection Agency. 2009a. ICLUS v1.2 user's manual: ArcGIS tools and datasets for modeling US housing density growth. Global Change Research Program, National Center for Environmental Assessment, Washington, D.C., USA. 〈http://www.epa.gov/ncea〉

United States Environmental Protection Agency. 2009b. Landuse scenarios: national-scale housing density scenarios consistent with climate change storylines. Global Change Research Program, National Center for Environmental Assessment, Washington, D.C., USA.

United States Geological Survey. 2004a. The national elevation dataset. United States Geological Survey, Washington, D.C., USA. 〈http://ned.usgs.gov/〉

United States Geological Survey. 2004b. The national hydrography dataset. United States Geological Survey, Washington, USA. 〈http://nhd.usgs.gov/〉

Vörösmarty, C. J., P. B. McIntyre, M. O. Gessner, D. Dudgeon, A. Prusevich, P. Green, S. Glidden, S. E. Bunn, C. A. Sullivan, C. R. Liermann, and P. M. Davies. 2010. Global threats to human water security and river biodiversity. Nature 467:555-561.

Webb, C. O., D. D. Ackerly, M. A. McPeek, and M. J. Donoghue. 2002. Phylogenies and community ecology. Annual Review of Ecology and Systematics 33:475-505.

Whittier, J. B., C. P. Paukert, J. D. Olden, K. L. Pitts, and A. L. Strecker. 2011. Lower Colorado River Basin aquatic gap analysis project: final report. U.S. Geological Survey, Gap Analysis Program, Reston, Virginia, USA.

\section{APPENDIX A}

Predictor variables used in species distribution models (Ecological Archives A021-135-A1).

\section{APPENDIX B}

Nonnative species that were modeled with MARS, as well as species included as point occurrences in Zonation (Ecological Archives A021-135-A2).

\section{APPENDIX C}

Methodological details of Zonation implementation (Ecological Archives A021-135-A3).

\section{APPENDIX D}

Native species traits used for calculations of functional diversity (Ecological Archives A021-135-A4).

\section{APPENDIX E}

Contemporary and future threats to native species persistence (Ecological Archives A021-135-A5).

\section{APPENDIX F}

Conservation ranking (\%) of the landscape averaged over taxonomic, functional, and phylogenetic diversity scenarios (Ecological Archives A021-135-A6).

\section{APPENDIX G}

Area of the top $10 \%$ of different conservation scenarios across future projected changes in temperature, precipitation, and impervious surface (Ecological Archives A021-135-A7).

\section{APPENDIX H}

Changes in the proportion of species distribution that remain as planning units in the basin are removed (Ecological Archives A021-135-A8).

\section{SUPPLEMENT}

Taxonomic, functional, and phylogenetic conservation priorities download for Google Earth (Ecological Archives A021-135-S1). 